Cipango Cahiers d'études japonaises

$20 \mid 2013$

Nouveaux regards sur les arts de la scène japonais I

\title{
Déploration de la mort de Higashi Yutaka (2000)
}

\section{Miri Yū}

Traducteur : Toshio Takemoto

\section{OpenEdition}

\section{Journals}

Édition électronique

URL : https://journals.openedition.org/cipango/1982

DOI : 10.4000/cipango.1982

ISSN : 2260-7706

Éditeur

INALCO

Édition imprimée

Date de publication : 30 octobre 2013

ISSN : 1164-5857

\section{Référence électronique}

Miri Yū, « Déploration de la mort de Higashi Yutaka (2000) », Cipango [En ligne], 20 | 2013, mis en ligne le 17 avril 2015, consulté le 30 juin 2021. URL : http://journals.openedition.org/cipango/1982 ; DOI : https://doi.org/10.4000/cipango.1982

Ce document a été généré automatiquement le 30 juin 2021.

\section{(c) (1) \$}

Cipango est mis à disposition selon les termes de la Licence Creative Commons Attribution - Pas d'Utilisation Commerciale 4.0 International. 


\section{Déploration de la mort de Higashi Yutaka (2000)}

\section{Miri Yū}

Traduction : Toshio Takemoto

\section{NOTE DE L'AUTEUR}

YŪ Miri 柳美里, «Higashi Yutaka wo itamu » 東由多加を悼む, in Sakana ga mita yume 魚が見た夢 (le Rêve du poisson), (2000), 2003, Tōkyō, Shinchōsha 新潮社, p. 317-319.

1 Me voilà face au portrait et aux cendres de feu Higashi Yutaka.

2 Nous nous sommes rencontrés voici quinze ans - j'avais alors seize ans, et Higashi, trente-neuf -, nous avons d'abord eu des relations de comédienne à metteur en scène, nous avons été amants, amis intimes, maître et élève, mari et femme, père et fille, frère et sœur, camarades, nous avons rompu et renoué tous ces rapports en dix ans de vie commune et, même après notre séparation, nous avons continué à nous voir sans pouvoir rompre nos liens. Puis, en 1999, presque simultanément à la découverte de ma grossesse et du cancer de Higashi, nous nous sommes remis à vivre ensemble.

3 Les Tōkyō Kid Brothers ont été lancés en 1969, un an après ma naissance. Je n'ai vu quasiment aucun de leurs chefs-d'œuvre, j'ignore les pièces des autres compagnies, je suis donc incapable de situer les Kid dans le théâtre contemporain, mais je suis sûre d'une chose: la mise en scène et la dramaturgie de Higashi Yutaka relèvent d'une méthode introuvable ailleurs.

Durant l'acting des stagiaires, la mise en voix d'un texte et l'entraînement du corps étaient secondaires, mais nous ne cessions les exercices de "pleurs», de " rires », de « colère ». Il procédait en nous faisant raconter devant tout le monde l'événement à ce jour le plus triste, le plus drôle, le plus fâcheux de notre vie, pour tirer de nous nos sentiments enfouis et les faire résonner. Higashi ne supportait pas les banales histoires de vie, il vérifiait la vérité des faits en nous faisant téléphoner sur le champ à nos 
parents et amis pour voir si nous ne mentions pas; il lançait parfois devant tout le monde : «Tu mens! »

Néanmoins, il n'exigeait pas que nous racontions la « réalité » telle quelle. Il récusait bien plutôt la « réalité ». Du moment que l'on parvenait à émouvoir les gens présents et à s'émouvoir soi-même, la fiction ne posait aucun problème.

Quand on devenait stagiaire, il nous demandait de lui remettre nos journaux intimes. L'été, nous avions notre devoir : «créer l'été ». Ce n'est pas arrivé chaque année, mais un autre exercice consistait à répéter poitrine nue, sans distinction de sexe. Higashi accomplissait pour les comédiens le saut de la «réalité » et du "quotidien », ce qui revenait aussi à ôter le masque qu'on portait dans la vie « quotidienne » pour montrer un visage démasqué.

7 "Je ne veux pas qu'on joue dans ma comédie musicale. C'est au théâtre, justement, que je veux voir l'homme. ».

8 Pour exhiber le vrai visage de «l'homme», Higashi nous faisait tenir un journal intime, puis le raconter devant tout le monde, interrogeant le passé que nous avions écrit pour faire ressurgir nos souffrances d'alors.

9 Par exemple, une nuit, j'ai décidé de me séparer de Higashi Yutaka. J'ai plié bagage avec l'aide de ma petite sœur ${ }^{1}$, j'ai laissé un mot sur une table et je suis rentrée chez moi comme si je déménageais à la cloche de bois. Quelques jours plus tard, lors de notre entraînement, Higashi m'a fait prendre la parole. Il a cité tel quel le mot que j'avais laissé. Je me suis retrouvée en situation de devoir lire à haute voix ma lettre privée devant un public, c'était insensé de la part de Higashi, et je lui en ai voulu.

Le 20 avril 2000 à 22 h 51, Higashi a rendu son dernier soupir à l'hôpital annexe de l'université Shōwa.

11 Aux obsèques, j'ai interrogé Madame Kitamura Yasuko, comédienne et membre de la production des Kid: «Vous n'organisez pas de spectacle en hommage?». Elle a dit: "Qui va le faire?", je n'ai su quoi répondre.

S'il s'agissait de donner des pièces de Terayama Shūji ou de Kara Jūro, contemporains de Higashi ayant déployé chacun une activité étonnante, d'autres metteurs en scène sauraient le faire. Mais recréer une comédie musicale créée et mise en scène par Higashi Yutaka, c'est impossible. Nul n'a aussi profondément blessé ni tant aimé les comédiens que Higashi. Résultat : certains comédiens succombaient à la folie, d'autres devenaient alcooliques ou se suicidaient.

Et moi, face à son portrait et à ses cendres, j'hésite à vivre encore.

\section{NOTES}

1. Yū Eri, cadette de Miri, était elle aussi comédienne des Tōkyō Kid Brothers. 